\title{
The Relative Prevalence of Typhoid and Malaria in Febrile Patients in Freetown, Sierra Leone
}

\author{
Michaella Siatta Kargbo, Lamin Daddy Massaquoi, Sallieu Kabay Samura, \\ Xiaojing Meng, Fei Zou* \\ Department of Occupational Health and Occupational Medicine, School of Public Health and Tropical \\ Medicine, Southern Medical University, Guangzhou, China \\ Email: kellakay@yahoo.com, ${ }^{*}$ zoufei616@163.com
}

Received 4 April 2014; revised 7 May 2014; accepted 20 May 2014

Copyright (C) 2014 by authors and Scientific Research Publishing Inc.

This work is licensed under the Creative Commons Attribution International License (CC BY). http://creativecommons.org/licenses/by/4.0/

(c) (i) Open Access

\begin{abstract}
Malaria and typhoid fever are debilitating diseases responsible for the deaths of thousands of lives annually. Over the last decade both diseases have received increasing attention with particular focus on malaria. However, recent reports indicate an increasing co-infection rate between malaria and typhoid fever. Familiar signs and symptoms of both diseases have led to the belief in some communities that it's a new disease. In this study, we investigated the relationship between malaria and typhi $\mathrm{O}$ and $\mathrm{H}$ antigens among patients reporting with fever. Patients reporting with fever from April 2013-March 2014 were recruited for the study. Our results showed that there was no association between having malaria and typhoid fever infection. However, having fever was associated with having both diseases. Also, fever among patients was more likely to be caused by Salmonella typhi $\mathrm{O}$ and $\mathrm{H}$ antigens than plasmodium parasites. Infections of both diseases were higher in wet season than in dry season. The study recommends that malaria and typhoid fever intervention programs are increased in endemic areas. Also attention should be paid to typhoid fever infection rates in the country.
\end{abstract}

\section{Keywords}

Fever, Malaria, Typhoid Fever, Widal Test, Co-Infection

\section{Introduction}

Malaria and typhoid fever are endemic diseases with life threatening consequences especially in Sub-Saharan

"Corresponding author.

How to cite this paper: Kargbo, M.S., et al. (2014) The Relative Prevalence of Typhoid and Malaria in Febrile Patients in Freetown, Sierra Leone. Open Journal of Preventive Medicine, 4, 338-346. http://dx.doi.org/10.4236/ojpm.2014.45041 
Africa. Malaria infection is caused by the plasmodium parasite through the bites of an infected vector, usually an anopheles mosquito. Four species of the plasmodium parasite cause malaria in humans ( $P$. falciparium, $P$. vivax, $P$. malaria and $P$. Ovale). However $P$. falciparium is the most common causative agent and contributes to the highest fatality. Typhoid fever is caused by a gram negative bacterium called Salmonella typhi. Infection usually occurs through ingestion of contaminated food or water. Serology tests usually measure for agglutinations of antibodies against flagella $(\mathrm{H})$ and somatic $(\mathrm{O})$ antigens of the bacterium. Both diseases have similar clinical manifestations such as fever, nausea, appetite loss, headache and constipation. Complications are common for both diseases and usually lead to death.

Malaria and typhoid fever are usually associated with areas or regions with high poverty and under development [1]. In 2012, the World Health Organization (WHO) estimated that there was an approximately 207 million cases of malaria with an estimated 627,000 deaths [2]. Annual typhoid fever infection is estimated at 21 million cases with a case fatality rate of $1 \%-4 \%$. These statistics become worse when related to countries where these diseases are endemic. 90\% of all malaria deaths occur in Sub-Saharan Africa [2]. According to a study by Crump et al., (2004) typhoid fever incidence rate for Asia, Africa and Latin America was 274/10, 50/10 and 53/10 respectively, compared to rates of 15/10, 3/10 and 1/10 for Oceana, Europe and North America respectively [3]. Despite these high rates, in recent years, there has been a decrease in malaria's morbidity and mortality (www.cdc.gov/features/worldmalariaday).

Geographic distribution of both diseases shows that a co-infection of both diseases is imperative. Also overlap in the social dynamics of communities with high incidence of both diseases gives further credence to the coinfection of both diseases [4]. Due to common clinical manifestations of both diseases, there is a common belief in most endemic communities that malaria and typhoid fever are concurrent diseases and therefore should be treated as such [1]. Diagnostics procedures for malaria and typhoid fever infections are crude and inaccurate in most of these communities, as a result data on co-infection are usually flawed and misleading [5].

In an endemic area such as Sierra Leone, there is an increase in the belief that co-infection is a new disease and should be treated as such. Also, most medical practitioners treat patients presenting with signs and symptoms of any one of the two diseases with treatments for both diseases. Considering the mutational property of the plasmodium parasite and Salmonella bacteria, drug misuse will lead to resistivity of both pathogens, as has been proven in recent years [2]. Understanding the relationship between typhoid fever and malaria with regard to patients presenting with a similar symptom such as fever, will help to improve knowledge and perspectives towards both diseases and also explain possible relationships (if any), that might exist between malaria and typhoid fever. In this study we investigated the relationship between malaria and typhoid fever infections among patients presenting with fever in a 12-month period at a referral hospital. We also investigated monthly trends of both diseases.

\section{Methodology}

\subsection{Study Site}

Study data was collected from the Kingharman Road Government Hospital. The hospital is a fully functioning government hospital with more than five hundred visits per day. It is located in the central part of Freetown, the capital city of Sierra Leone. Sierra Leone is in the western part of Africa with a size of about 71,740 km square (27,699 square miles). In the last census report, Sierra Leone had a population of 6 million (2011 United Nations estimate) and the population of Freetown was approximately 772,873. The ratio of male to female in was 0.97 male(s)/female of the population are under the age of 30. The country has a tropical climate with a wet season from May to October and a dry season from November to April. It has an average temperature of about $27^{\circ} \mathrm{C}$ and an annual rainfall average of $3150 \mathrm{~mm}$.

The hospital is one of the main referral hospitals in Sierra Leone and is one of the main surveillance units for diseases in the country, especially malaria and typhoid. On a daily basis, the hospital has about 150 to 200 patients tested for malaria and typhoid combined.

\subsection{Study Participants and Sample Collection}

The study was conducted from April 2013 to March 2014. Patients with fever reporting for malaria and typhoid testing were recruited in the study. A total of 11,069 patients with fever were recruited during the study period. 
Patients were tested for malaria and typhoid $(\mathrm{O}$ and $\mathrm{H})$ infections. Study participants included males (47.38\%), and females (52.62\%). All patients were above the age of five. Under-fives were not included in the study because of inconsistencies in recruiting them for the study and also issues involving safety and consent solicitation.

Trained and licensed laboratory technicians obtained blood samples from all enrolled participants. Blood samples of about $3 \mathrm{mls}$ were collected from the vein of each patient and tested for malaria parasites, Salmonella typhi $\mathrm{O}$ and $\mathrm{H}$ antibodies. Samples were stored in test tubes and stored at $15^{\circ} \mathrm{C}-30^{\circ} \mathrm{C}$ prior to laboratory analysis.

\subsection{Laboratory Analysis}

Conventional light microscopy method was used for confirmation of malaria. This is one the most popular and established method for malaria laboratory confirmation in the tropics and most developing societies. This method involves making a thick and thin dry blood film. The dry blood film was then stained with Giemsa and examined under the microscope, using the oil immersion objective lens. The patient was confirmed of having malaria parasites if stained parasites are seen by the technician. The parasites were counted by a simpler method called the plus system which uses a code of between one and four plus signs, as follows:

$$
\begin{aligned}
& +=1-10 \text { parasites per } 100 \text { thick film fields } \\
& ++=11-100 \text { parasites per } 100 \text { thick film fields } \\
& +++=1-10 \text { parasites per single thick film field }
\end{aligned}
$$

Serological diagnosis was carried out using widal agglutination test to determine the antibody titres of the sera against salmonella $\mathrm{H}$ (flagella) and $\mathrm{O}$ (somatic) antigens. Widal test is the main method for typhoid fever diagnosis in many African countries like Sierra Leone. The serological testing was done in accordance with manufacturers guidelines. The significant in this hospital were figures $\geq 1: 80$ for both typhi $\mathrm{O}$ and $\mathrm{H}$.

\subsection{Statistical Analysis}

Data were analyzed using SPSS 20.0. Chi square test was used for significance inspection and Pearson's correlation coefficient was for the inspection of associations.

\subsection{Ethical Considerations}

Before data collection, permission was solicited from the hospital ethics committee and confirmed by the ethics committee of the Ministry of Health and Sanitation. Laboratory procedures and personnel were scrutinized and approved by the safety department of the hospital. Informed consent was solicited from patients or their guardians (for patients under 18 years).

\section{Results}

\subsection{General Characteristics and Age Distribution}

The study investigated the association between malaria, S. typhi $\mathrm{O}$ and S. typhi $\mathrm{H}$ infections among patients with fever symptoms that reported for testing at the Kingharman road government hospital from April 2013 to March 2014. During the study period, a total of 11,069 fever patients reported for testing, of these, 5245 (47.38\%) were males and 5824 (52.62\%) were females. Only 147 (1.3\%) fever patients did not test positive for any of the three diseases or infection. A total of 8849 (79.94\%) fever patients tested positive for the plasmodium parasite. Among these, positive male cases were $4180(37.76 \%)$ and female positive cases were 4669, $\chi^{2}=0.431, p<$ 0.05. 5992, 2809 and 48 patients that tested positive for the plasmodium parasite, had parasites loads of +, ++ and +++ respectively. Patients with reactive widal agglutinations titres for S. typhi O and S. typhi H were 9247 (83.54\%) and 9603 (86.75\%) respectively. Male S. typhi O and S. typhi H cases were 4336 and 4911 respectively. Female S. typhi O cases were 4911 and S. typhi H female cases were 5098. 4974 cases had S. typhi O titres $\geq 1: 80$ and 4581 cases had $S$. typhi $\mathrm{H}$ titres $\geq 1: 80$ (Table 1 ).

Most of the cases tested were with the age groups of $5-34$, consisting of $60.94 \%$ for malaria positive cases, $34.55 \%$ for typhi $\mathrm{O}$ and $31.98 \%$ for typhi $\mathrm{H}$ cases $\geq 1: 80$ (Table 2 ). Not surprisingly, this age group (5 - 34 years) accounted for most of the positive malaria and typhi $\mathrm{O}$ and $\mathrm{H}$ cases. However, compared to typhi $\mathrm{O}$ and $\mathrm{H}$ cases, 
Table 1. Gender and disease distribution among all fever patients from April 2013-March 2014.

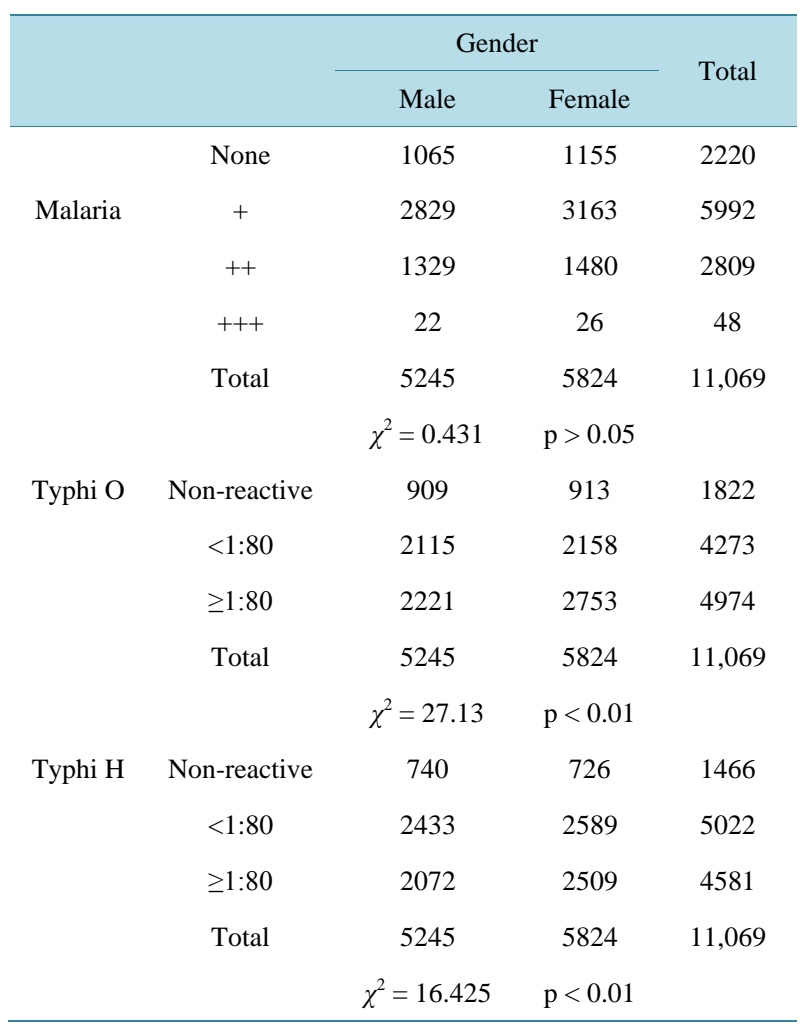

Table 2. Age distribution of fever patients testing for malaria, S. typhi O and S. typhi H.

\begin{tabular}{|c|c|c|c|c|c|c|c|c|c|c|c|}
\hline & & \multicolumn{4}{|c|}{ Malaria } & \multicolumn{3}{|c|}{ Typhi O } & \multicolumn{3}{|c|}{ Typhi H } \\
\hline & & \multicolumn{4}{|c|}{ Parasite load } & \multicolumn{3}{|c|}{ Titre } & \multicolumn{3}{|c|}{ Titre } \\
\hline & & Not seen & + & ++ & +++ & Non-reactive & $<1: 80$ & $\geq 1: 80$ & Non-reactive & $<1: 80$ & $\geq 1: 80$ \\
\hline \multirow[t]{14}{*}{ Age group } & $5-9$ & 336 & 899 & 404 & 8 & 260 & 661 & 726 & 215 & 736 & 696 \\
\hline & $10-14$ & 245 & 680 & 344 & 4 & 204 & 452 & 617 & 163 & 573 & 537 \\
\hline & $15-19$ & 296 & 792 & 362 & 3 & 246 & 550 & 657 & 199 & 637 & 617 \\
\hline & $20-24$ & 304 & 845 & 375 & 7 & 255 & 563 & 713 & 204 & 662 & 665 \\
\hline & $25-29$ & 251 & 665 & 328 & 7 & 185 & 520 & 546 & 152 & 590 & 509 \\
\hline & $30-34$ & 270 & 699 & 314 & 9 & 222 & 505 & 565 & 189 & 587 & 516 \\
\hline & $35-39$ & 96 & 254 & 132 & 1 & 77 & 166 & 240 & 67 & 229 & 187 \\
\hline & $40-44$ & 112 & 329 & 151 & 3 & 97 & 235 & 263 & 84 & 291 & 220 \\
\hline & $45-49$ & 66 & 184 & 83 & 3 & 66 & 142 & 128 & 40 & 160 & 136 \\
\hline & $50-54$ & 94 & 240 & 125 & 1 & 90 & 183 & 187 & 64 & 205 & 191 \\
\hline & $55-59$ & 29 & 94 & 40 & 0 & 33 & 65 & 65 & 14 & 80 & 69 \\
\hline & $60-64$ & 70 & 169 & 78 & 1 & 43 & 120 & 155 & 41 & 143 & 134 \\
\hline & $65-70$ & 18 & 27 & 19 & 0 & 15 & 25 & 24 & 13 & 26 & 25 \\
\hline & $>70$ & 33 & 115 & 54 & 1 & 29 & 86 & 88 & 21 & 103 & 79 \\
\hline
\end{tabular}

+= 1 - 10 parasites per 100 thick film fields; ++ = 11 - 100 parasites per 100 thick film fields; +++ = 1 - 10 parasites per single thick film field; +++ = more than 10 parasites per single thick film field. 
parasites load in patients having the plasmodium parasite were lower (in terms of causing malaria symptoms) than typhi $\mathrm{O}$ and $\mathrm{H}$ cases with titres $\geq 1: 80$ (also in terms of causing diseases).

\subsection{Distribution of Malaria, Typhi 0 and Typhi $H$}

Table 3 shows the distribution of malaria parasite load, S. typhi $\mathrm{O}$ and $\mathrm{H}$ widal agglutination titres among fever patients. Among the 11,069 fever patients tested for the plasmodium parasite, S. typhi O and S. typhi H, only 147 (1.3\%) tested negative or non-reactive for either the pathogen or bacteria. 66\% (7353) of cases had all three infections. 1894 negative cases of malaria were reactive for both $S$. typhi $\mathrm{O}$ and $S$. typhi $\mathrm{H}$ titres, of these, 422 cases had titres $<1: 80$ for $S$. typhi $\mathrm{O}$ and $S$. typhi $\mathrm{H}$. Also, 324 cases had titres $\geq 1: 80$ (Table 3). 403 non-reactive cases for S. typhi $\mathrm{H}$ and S. typhi $\mathrm{O}$ had + malaria parasite load and 301 cases with malaria parasite load of ++ were reactive for both $S$. typhi $\mathrm{O}$ and $S$. typhi H. Only 48 patients had +++ malaria parasite load, among them, 3 were non-reactive for $S$. typhi $\mathrm{O}$ and $S$. typhi $\mathrm{H}, 20$ had titres $<1: 80$ for $S$. typhi $\mathrm{O}$ and $\mathrm{H}$ and 11 had titres $\geq 1: 80$ for S. typhi O and H. Also from Table 3, among fever patients with S. typhi O and typhi H, only 7\% (854) were non-reactive for either $S$. typhi O or $S$. typhi $\mathrm{H}$. 2451 patients had titres of $<1: 80$ for $S$. typhi $\mathrm{O}$ and $\mathrm{H}$ and also 2655 had titres $\geq 1: 80$ for S. typhi O and S. typhi H (Table 3).

\subsection{Association between Malaria, Typhi $\mathbf{O}$ and Typhi $\mathbf{H}$}

Results from Table 4 show a significantly strong positive association between presence of the parasite or bacteria and fever.

Table 3. Malaria, typhi $\mathrm{O}$ and typhi $\mathrm{H}$ distribution among all fever patients from April 2013-March 2014.

\begin{tabular}{|c|c|c|c|c|c|}
\hline \multirow[t]{3}{*}{ Malaria } & \multicolumn{4}{|c|}{ Typhi H } & \multirow[t]{2}{*}{ Total } \\
\hline & & Non-reactive & $<1: 80$ & $\geq 1: 80$ & \\
\hline & \multicolumn{5}{|l|}{ Typhi O } \\
\hline \multirow{6}{*}{ Not seen } & Non-reactive & 147 & 98 & 81 & 326 \\
\hline & $<1: 80$ & 63 & 422 & 324 & 809 \\
\hline & $\geq 1: 80$ & 64 & 467 & 554 & 1085 \\
\hline & Total & 274 & 987 & 959 & 2220 \\
\hline & Non-reactive & 403 & 272 & 261 & 936 \\
\hline & $<1: 80$ & 169 & 1304 & 865 & 2338 \\
\hline \multirow[t]{4}{*}{+} & $\geq 1: 80$ & 134 & 1095 & 1489 & 2718 \\
\hline & Total & 706 & 2671 & 2615 & 5992 \\
\hline & Non-reactive & 301 & 157 & 97 & 555 \\
\hline & $<1: 80$ & 103 & 705 & 295 & 1103 \\
\hline \multirow[t]{4}{*}{++} & $\geq 1: 80$ & 77 & 473 & 601 & 1151 \\
\hline & Total & 481 & 1335 & 993 & 2809 \\
\hline & Non-reactive & 3 & 1 & 1 & 5 \\
\hline & $<1: 80$ & 1 & 20 & 2 & 23 \\
\hline \multirow[t]{2}{*}{+++} & $\geq 1: 80$ & 1 & 8 & 11 & 20 \\
\hline & Total & 5 & 29 & 14 & 48 \\
\hline \multirow[t]{4}{*}{ Total } & Non-reactive & 854 & 528 & 440 & 1822 \\
\hline & $<1: 80$ & 336 & 2451 & 1486 & 4273 \\
\hline & $\geq 1: 80$ & 276 & 2043 & 2655 & 4974 \\
\hline & Total & 1466 & 5022 & 4581 & 11069 \\
\hline
\end{tabular}


Table 4. Pearson’s correlation coefficient for gender, age group, malaria cases and typhi O and H cases.

\begin{tabular}{|c|c|c|c|c|c|c|c|c|c|}
\hline & & Gender & $\begin{array}{l}\text { Age } \\
\text { group }\end{array}$ & $\begin{array}{c}\text { Positive } \\
\text { malaria cases } \\
\text { per parasite } \\
\text { load }\end{array}$ & $\begin{array}{c}\text { All } \\
\text { positive } \\
\text { malaria } \\
\text { cases }\end{array}$ & $\begin{array}{c}\text { Typhi O } \\
\text { cases per } \\
\text { bacteria } \\
\text { load }\end{array}$ & $\begin{array}{c}\text { Typhi H } \\
\text { cases per } \\
\text { bacteria } \\
\text { load }\end{array}$ & $\begin{array}{c}\text { All } \\
\text { positive } \\
\text { typhi O } \\
\text { cases }\end{array}$ & $\begin{array}{c}\text { All } \\
\text { positive } \\
\text { typhi H } \\
\text { cases }\end{array}$ \\
\hline Gender & $\mathrm{r}$ & - & $0.021^{*}$ & 0.004 & 0.006 & $0.045^{* *}$ & $0.038^{* *}$ & $0.022^{*}$ & $0.023^{*}$ \\
\hline Age group & $\mathrm{r}$ & $0.021^{*}$ & - & 0.004 & 0.001 & -0.017 & -0.012 & -0.01 & 0.001 \\
\hline $\begin{array}{l}\text { Positive malaria cases } \\
\text { per parasite load }\end{array}$ & $r$ & 0.004 & 0.004 & - & $0.778^{* *}$ & $-0.059^{* *}$ & $-0.067^{* *}$ & $-0.044^{* *}$ & $-0.048^{* *}$ \\
\hline All positive malaria cases & $\mathrm{r}$ & 0.006 & 0.001 & $0.778^{* *}$ & - & $-0.039^{* *}$ & $-0.020^{*}$ & $-0.024^{*}$ & -0.012 \\
\hline Typhi O cases per bacteria load & $\mathrm{r}$ & $0.045^{* *}$ & -0.017 & $-0.059^{* *}$ & $-0.039^{* *}$ & - & $0.345^{* *}$ & $0.780^{* *}$ & $0.363^{* *}$ \\
\hline Typhi H cases per bacteria load & $\mathrm{r}$ & $0.038^{* *}$ & -0.012 & $-0.067^{* *}$ & $-0.020^{*}$ & $0.345^{* *}$ & - & $0.330^{* *}$ & $0.730^{* *}$ \\
\hline All positive typhi O cases & $\mathrm{r}$ & $0.022^{*}$ & -0.01 & $-0.044^{* *}$ & $-0.024^{*}$ & $0.780^{* *}$ & $0.330^{* *}$ & - & $0.437^{* *}$ \\
\hline All positive typhi $\mathrm{H}$ cases & $\mathrm{r}$ & $0.023^{*}$ & 0.001 & $-0.048^{* *}$ & -0.012 & $0.363^{* *}$ & $0.730^{* *}$ & $0.437^{* *}$ & - \\
\hline
\end{tabular}

${ }^{*}$ Correlation is significant at the 0.05 level (2-tailed). ${ }^{* *}$ Correlation is significant at the 0.01 level (2-tailed).

Correlation analysis between fever patients and patients with $\geq 10$ plasmodium parasites per single thick film field was $\mathrm{r}=0.778, \mathrm{p}<0.01$. Also, association between fever patients and $S$. typhi $\mathrm{O}$ and $\mathrm{H}$ cases was $\mathrm{r}=0.780$, $\mathrm{p}<0.01$ and $\mathrm{r}=0.730, \mathrm{p}<0.01$ respectively. However, correlation was weak and negative between malaria and S. typhi O, $\mathrm{r}=-0.059$, $\mathrm{p}<0.01$. Association was also weak between malaria and $S$. typhi $\mathrm{H}, \mathrm{r}=-0.067, \mathrm{p}<0.01$. There was positive association between $S$. typhi $\mathrm{O}$ and $S$. typhi $\mathrm{H}$ cases with titres $\geq 1: 80, \mathrm{r}=0.345, \mathrm{p}<0.01$.

Association between gender and all three diseases was weak, but significant $(\mathrm{p}<0.05)$ for $S$. typhi O and $S$. typhi $\mathrm{H}$.

\subsection{Malaria, Typhi 0 and Typhi H Monthly Trend}

Monthly trend for malaria, S. typhi O and S. typhi H followed almost similar trend (Figure 1).

Trend analysis for malaria, during the 12 month period was, $\chi^{2}=16.926, \mathrm{p}<0.01$. S. typhi O and S. typhi $\mathrm{H}$ chi square trend analysis were $\chi^{2}=16.425, \mathrm{p}<0.01$ and $\chi^{2}=0.10604, \mathrm{p}>0.05$ respectively. For all three infections, the lowest cases were recorded in March. Malaria, S. typhi O and S. typhi H cases in March were 483, 453 and 458 respectively. The highest cases for all three diseases were recorded in June and July. Malaria cases in June and July were 1054 and 1163 respectively, S. typhi O cases were 1173 and 1126 respectively for June and July and S. typhi H cases for June and July were 1184 and 1204 respectively. Cases increase sharply for all three diseases from May to June, with an increase of almost 30\%. Also, there was a decline in the number of cases testing positive for malaria or reactive for S. typhi $\mathrm{O}$ and $\mathrm{H}$ in the months from July to August and August to September.

\section{Discussion}

This study investigated the association and monthly trend of Malaria, S. typhi O and S. typhi $\mathrm{H}$ among fever patients at the Kingharman Government Hospital Freetown in a 12-month period. Gender had no significant relationship with malaria, but was significant for S. typhi $\mathrm{O}$ and typhi H. Females were significantly more infected than males for both S. typhi $\mathrm{O}$ and S. typhi $\mathrm{H}$. This result is in line with results from the study conducted by Levine et al. [6]. Considering the mode of transmission of typhoid, in endemic areas it is common for women to be more affected than men. Also, infection rate among age groups was consistent with national figures, indicating a high fever incidence as well as high malaria and typhi $\mathrm{O}$ and $\mathrm{H}$ infection rates. These results despite discouraging have been the trend in malaria and typhi $\mathrm{O}$ and $\mathrm{H}$ infections for decades now. Almost every fever patient was positive or reactive for at least one of the diseases in this study. The high rate of infection can be attributed to poor sanitation hygiene, other socio-economic factors and also the optimum temperatures that favors the reproductive cycle of these bacteria or parasites [7]-[9]. Also, over $60 \%$ of all patients were infected with all three 

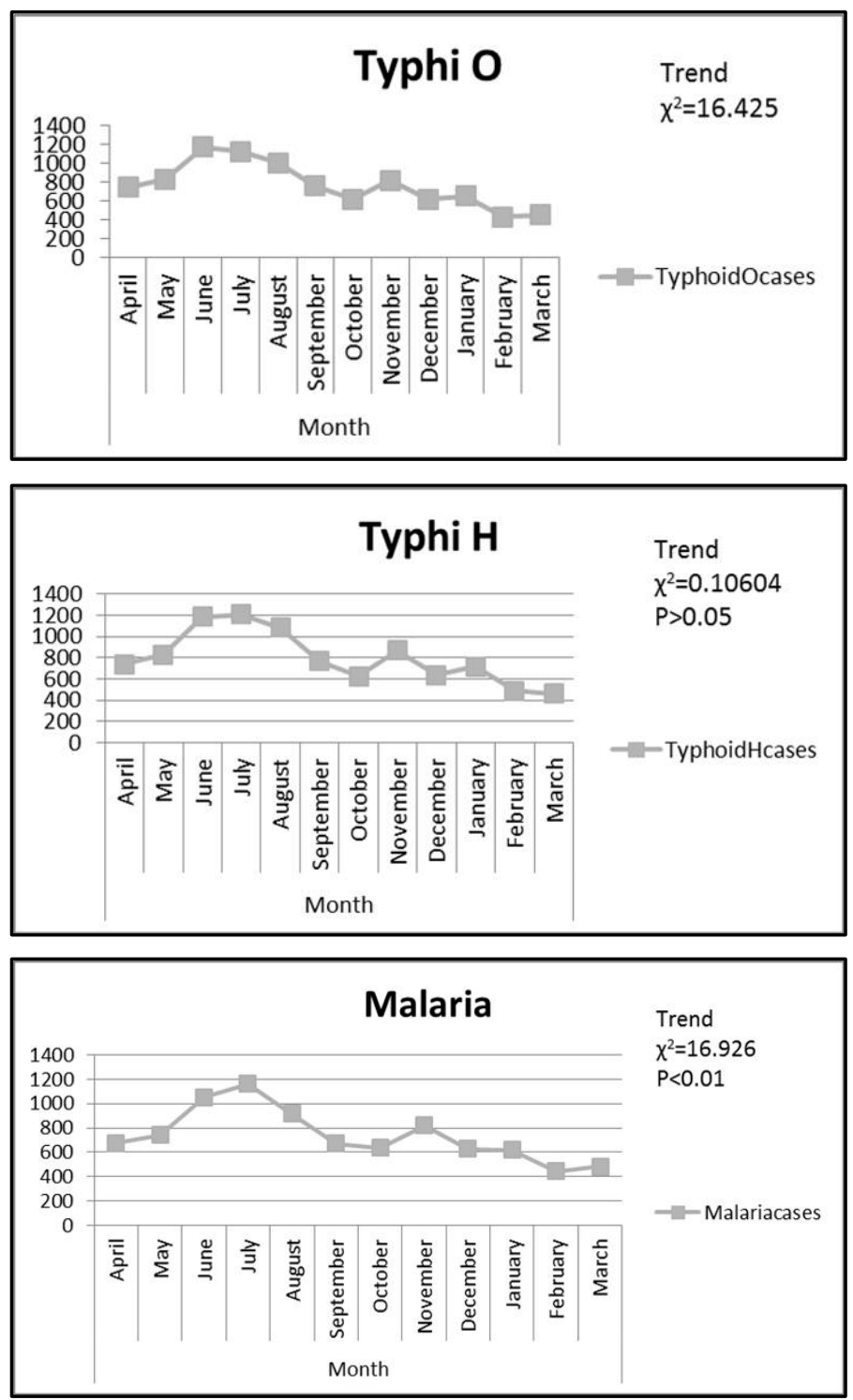

Figure 1. Monthly malaria, typhi $\mathrm{O}$ and $\mathrm{H}$ trend among fever patients from April 2013-March 2014.

diseases. Malaria cases with parasite loads of less than 10 parasites per 100 thick film fields were higher than cases with parasite loads of more than 10 parasites per 100 thick film fields. Major interventions aimed at reducing malaria morbidity and fatalities are some of the reasons for low plasmodium parasite loads [10]. Accessibility and availability of effective antimalarial drugs are other factors that might be responsible for lower malaria parasite load [11]. S. typhi $\mathrm{O}$ and $\mathrm{H}$ cases were higher than malaria cases. Compared to previous years when malaria infections were greater than typhoid infections, there has been a reverse in this trend in recent years [12] [13]. These results were not surprising, taking into consideration the resistance of the Salmonella typhi bacterium to antibiotics and also the complex nature of typhoid [14]-[17]. Despite high S. typhi O and H infections especially in endemic areas, interventions aimed at reducing typhoid infections have been lower compared to malaria interventions. These results show that vigorous health interventions can be highly effective in reducing disease morbidity and mortality. Considering the public health relevance of typhoid fever, higher infection rates should be treated as a public health emergency and trend reversed as to lower and acceptable values to avoid an outbreak or possible epidemics. In line with previous studies, this study did not find any association between malaria and typhoid fever infections [12] [18] [19]. 
There was a strong association between having fever and having malaria parasites with loads greater than 10 parasites per 100 thick film fields. Similar results were recorded by Anmah et al., (1999) [20]. Also, there was strong positive association between $S$. typhi $\mathrm{O}$ and $\mathrm{H}$ infections with titres $\geq 1: 80$ and fever patients. These associations' further helps to consolidate already known data that malaria and S. typhi $\mathrm{H}$ and $\mathrm{O}$ infections are the main causes of fever symptoms in areas endemic to the two diseases [19] [21].

Malaria and typhoid fever infections are higher in the raining/wet season than drier seasons. This is mainly due to the mode of transmission and reproductive cycles of the plasmodium parasite and Salmonella bacteria. This study recorded higher malaria and typhoid infections especially in the peak periods of the raining season and lower rates in the peak period of the dry season. Infections for both diseases were high from the months of June-August, coinciding with months of heavy rainfall. Trend analysis from this study showed a reduction in the number of malaria and typhoid cases as rainfall reduces. However, there was an increase in the number of malaria and typhoid cases from October to November. Lower temperatures and reduced water levels that favor disease transmission is a possible reason for the increase in rate from October-November.

\section{Conclusion}

Almost every patient presenting with fever symptoms had malaria, S. typhi O or S. typhi $\mathrm{H}$ infections, but $S$. typhi $\mathrm{O}$ and $\mathrm{H}$ infections were higher than malaria infections. There was no association between patients having malaria and typhoid fever. However, there was a strong association between having fever and that of having malaria or S. typhi O and S. typhi $\mathrm{H}$ infections. Also fever among patients was more likely to be caused by Salmonella typhi $\mathrm{O}$ and $\mathrm{H}$ antigens than plasmodium parasites. Malaria, S. typhi $\mathrm{O}$ and $\mathrm{H}$ infections are higher in the raining/wet periods of the year than in drier periods. The study recommends that intervention programs aimed at reducing malaria and typhoid infections are increased in endemic areas, especially in the wet seasons. Also particular attention should be paid to typhoid fever infection rates in the country.

\section{References}

[1] Uneke, C.J. (2008) Concurrent Malaria and Typhoid Fever in the Tropics: The Diagnostic Challenges and Public Health Implications. Journal of Vector Borne Diseases, 45, 133-142.

[2] WHO (2013) Factsheet on the World Malaria Report 2013.

[3] Crump, J.A., Luby, S.P. and Mintz, E.D. (2004) The Global Burden of Typhoid Fever. Bulletin of the World Health Organization, 82, 346-353.

[4] Keong, B.C. and Sulaiman, W. (2006) Typhoid and Malaria Co-Infection-An Interesting Finding in the Investigation of a Tropical Fever. The Malaysian Journal of Medical Sciences: MJMS, 13, 74-75.

[5] Alhassan, H.M., Shidali, N.N., Manga, S.B., Abdullahi, K. and Hamid, K.M. (2012) Co-Infection Profile of Salmonella typhi and Malaria Parasite in Sokoto-Nigeria. Global Journal of Science, Engineering and Technology, 2, 13-20.

[6] Levine, M.M., Black, R.E. and Lanata, C. (1982) Precise Estimation of the Numbers of Chronic Carriers of Salmonella typhi in Santiago, Chile, an Endemic Area. The Journal of Infectious Diseases, 146, 724-726. http://dx.doi.org/10.1093/infdis/146.6.724

[7] Sharma, P.K., Ramakrishnan, R., Hutin, Y., Manickam, P. and Gupte, M.D. (2009) Risk Factors for Typhoid in Darjeeling, West Bengal, India: Evidence for Practical Action. Tropical Medicine \& International Health: TM \& IH, 14, 696-702. http://dx.doi.org/10.1111/j.1365-3156.2009.02283.x

[8] Luby, S.P., Faizan, M.K., Fisher-Hoch, S.P., Syed, A., Mintz, E.D., Bhutta, Z.A. and McCormick, J.B. (1998) Risk Factors for Typhoid Fever in an Endemic Setting, Karachi, Pakistan. Epidemiology and Infection, 120, 129-138. http://dx.doi.org/10.1017/S0950268897008558

[9] Bhan, M.K., Bahl, R., Sazawal, S., Sinha, A., Kumar, R., Mahalanabis, D. and Clemens, J.D. (2002) Association between Helicobacter pylori Infection and Increased Risk of Typhoid Fever. The Journal of Infectious Diseases, 186, 1857-1860. http://dx.doi.org/10.1086/345762

[10] WHO (2009) World Malaria Report. World Health Organization.

[11] Diap, G., Amuasi, J., Boakye, I., Sevcsik, A.M. and Pecoul, B. (2010) Anti-Malarial Market and Policy Surveys in Sub-Saharan Africa. Malaria Journal, 9, S1. http://dx.doi.org/10.1186/1475-2875-9-S1-S1

[12] Mbuh, F.A., Galadima, M. and Ogbadu, L. (2003) Rate of Co-Infection with Malaria Parasites and Salmonella typhi in Zaria, Kaduna State, Nigeria. Annals of African Medicine, 2, 64-67.

[13] Jhaveri, K.N., Nandwani, S.K., Mehta, P.K., Surati, R.R. and Parmar, B.D. (1995) False Positive Modified Widal Test 
in Acute Malaria. The Journal of the Association of Physicians of India, 43, 754-755.

[14] Lynch, M.F., Blanton, E.M., Bulens, S., Polyak, C., Vojdani, J., Stevenson, J., Medalla, F., Barzilay, E., Joyce, K., Barrett, T., et al. (2009) Typhoid Fever in the United States, 1999-2006. JAMA: The Journal of the American Medical Association, 302, 859-865. http://dx.doi.org/10.1001/jama.2009.1229

[15] Bahrmand, A.R. and Velayati, A.A. (1997) Antimicrobial Resistance Pattern and Plasmid Profile of Salmonella typhi Isolated from an Outbreak in Tehran Province. Scandinavian Journal of Infectious Diseases, 29, 265-269. http://dx.doi.org/10.3109/00365549709019040

[16] Mitra, R., Houshang, M.A., Hamid, H.S., Maryam, D., Reza, M.A., Shima, H. and Marzieh, N. (2009) Clinical Features of Patients with Typhoid Fever and Drug Resistance of the Causative Isolates in Western Iran. Tropical Doctor, 39, 223-224. http://dx.doi.org/10.1258/td.2009.090046

[17] Karki, S., Shakya, P., Cheng, A.C., Dumre, S.P. and Leder, K. (2013) Trends of Etiology and Drug Resistance in Enteric Fever in the Last Two Decades in Nepal: A Systematic Review and Meta-Analysis. Clinical Infectious Diseases: An Official Publication of the Infectious Diseases Society of America, 57, e167-e176. http://dx.doi.org/10.1093/cid/cit563

[18] Ezeagwuna, D.A., Emele, F.E., Agbakoba, N.R., Ogbuagu, C.N., Ekejindu, I.M. and Orji, N.M. (2010) Investigating the Relationship between Malaria Parasitaemia and Widal Positivity. The Internet Journal of Tropical Medicine, 7.

[19] Igharo, E.A., Osazuwa, F., Ajayi, S.A., Ebueku, A. and Igbinigie, O. (2012) Dual Infection with Typhoid and Malaria in Febrile Patients in Ikare Akoko, Nigeria. International Journal of Tropical Medicine, 7, 49-52. http://dx.doi.org/10.3923/ijtmed.2012.49.52

[20] Ammah, A., Nkuo-Akenji, T., Ndip, R. and Deas, J.E. (1999) An Update on Concurrent Malaria and Typhoid Fever in Cameroon. Transactions of the Royal Society of Tropical Medicine and Hygiene, 93, 127-129. http://dx.doi.org/10.1016/S0035-9203(99)90282-1

[21] Baba, M., Logue, C.H., Oderinde, B., Abdulmaleek, H., Williams, J., Lewis, J., Laws, T.R., Hewson, R., Marcello, A., and D'Agaro, P. (2013) Evidence of Arbovirus Co-Infection in Suspected Febrile Malaria and Typhoid Patients in Nigeria. Journal of Infection in Developing Countries, 7, 51-59. http://dx.doi.org/10.3855/jidc.2411 